\title{
Clinical efficacy of probiotics on feeding intolerance in preterm infants: a systematic review and meta-analysis
}

\author{
Wei Zhang' ${ }^{1 \#}$, Shiqun Wang ${ }^{2 \#}$, Yu Xing ${ }^{3}$, Hongyi Wang ${ }^{3}$, Binsha Fu ${ }^{4}$, Mingjia Long ${ }^{2}$, Juan Cao ${ }^{3}$ \\ ${ }^{1}$ Department of Neonatology, Hainan Women and Children's Medical Center, Haikou, China; ${ }^{2}$ Department of Pediatrics, Qionghai Hospital of \\ Traditional Chinese Medicine, Qionghai, China; ${ }^{3}$ Department of Pediatrics, Hainan Modern Women and Children's Hospital, Haikou, China; \\ ${ }^{4}$ Department of Pediatrics, Hainan General Hospital (Hainan Affiliated Hospital of Hainan Medical University), Haikou, China \\ Contributions: (I) Conception and design: W Zhang, S Wang; (II) Administrative support: J Cao; (III) Provision of study materials or patients: W \\ Zhang, S Wang, Y Xing, H Wang, B Fu, M Long; (IV) Collection and assembly of data: W Zhang, S Wang; (V) Data analysis and interpretation: W \\ Zhang, S Wang, Y Xing, H Wang; (VI) Manuscript writing: All authors; (VII) Final approval of manuscript: All authors. \\ "These authors contributed equally to this work and should be considered as co-first authors. \\ Correspondence to: Juan Cao. Department of Pediatrics, Hainan Modern Women and Children's Hospital, Haikou 571100, China. \\ Email: caojuan8297@163.com.
}

Background: The physiological organ system of premature infants is still very immature, so it is easy to result feeding intolerance. Therefore, effective probiotic supplementation plays a very important role and clinical research significance in promoting the growth and development of preterm infants, improving the quality of life and improving the occurrence of feeding intolerance. To explore the clinical effect of probiotics on feeding intolerance (FI) in preterm infants by meta-analysis.

Methods: The PubMed, Web of Science, EMBASE and MEDLINE literature databases were searched for relevant literature. The literature related to the clinical effect of probiotics on FI in preterm infants was published from January 2002 to January 2021. RevMan 5.3 was used to calculate the reinforcement mean difference (MD) and evaluate the publication bias.

Results: Nine articles were included, involving a total of 1,244 preterm infants with FI. Through the sensitivity analysis of each excluded study, the results showed no significant differences. Compared with patients in the control group, the probiotics group had significant improvements $(\mathrm{P}<0.1)$ in the total intestinal feeding time ( $\mathrm{MD}=-2.54,95 \% \mathrm{CI}:-3.57,-1.52, \mathrm{P}<0.00001)$, weight gain $(\mathrm{MD}=23.81,95 \% \mathrm{CI}$ : 19.75, 27.81, $\mathrm{P}<0.00001)$, maximum enteral feeding ( $\mathrm{MD}=6.41,95 \% \mathrm{CI}: 1.94,10.88, \mathrm{P}=0.005)$, hospital stay $(\mathrm{MD}=-5.18,95 \% \mathrm{CI}:-5.63,-4.74, \mathrm{P}<0.00001)$, incidence of $\mathrm{FI}$ [odds rate $(\mathrm{OR})=0.38,95 \% \mathrm{CI}: 0.27,0.55$, $\mathrm{P}<0.00001]$ and improvement in the gastrointestinal tract ( $\mathrm{OR}=2.34,95 \% \mathrm{CI}: 1.07,5.14, \mathrm{P}=0.03)$.

Discussion: Our study shows that the use of probiotics can promote the early growth of preterm infants and effectively improve the occurrence of FI in preterm infants.

Keywords: Probiotics; clinical efficacy; feeding intolerance (FI); preterm infants; meta-analysis

Submitted Dec 14, 2021. Accepted for publication Jan 20, 2022.

doi: 10.21037/tp-21-624

View this article at: https://dx.doi.org/10.21037/tp-21-624

\section{Introduction}

With the development of modern medicine and human nutrition, the survival rate of preterm infants has been significantly improved. However, due to the immature development of various physiological organs of preterm infants, they often suffer from feeding intolerance (FI), such as large gastrointestinal residues, abdominal distension, low average weight and vomiting $(1,2)$. This not only makes them unable to effectively absorb the nutrients they ingest but also causes inflammation of the gastrointestinal tract, such as enteritis, colitis and gastritis $(3,4)$. Therefore, taking effective drugs, such as cisapride, mosapride 


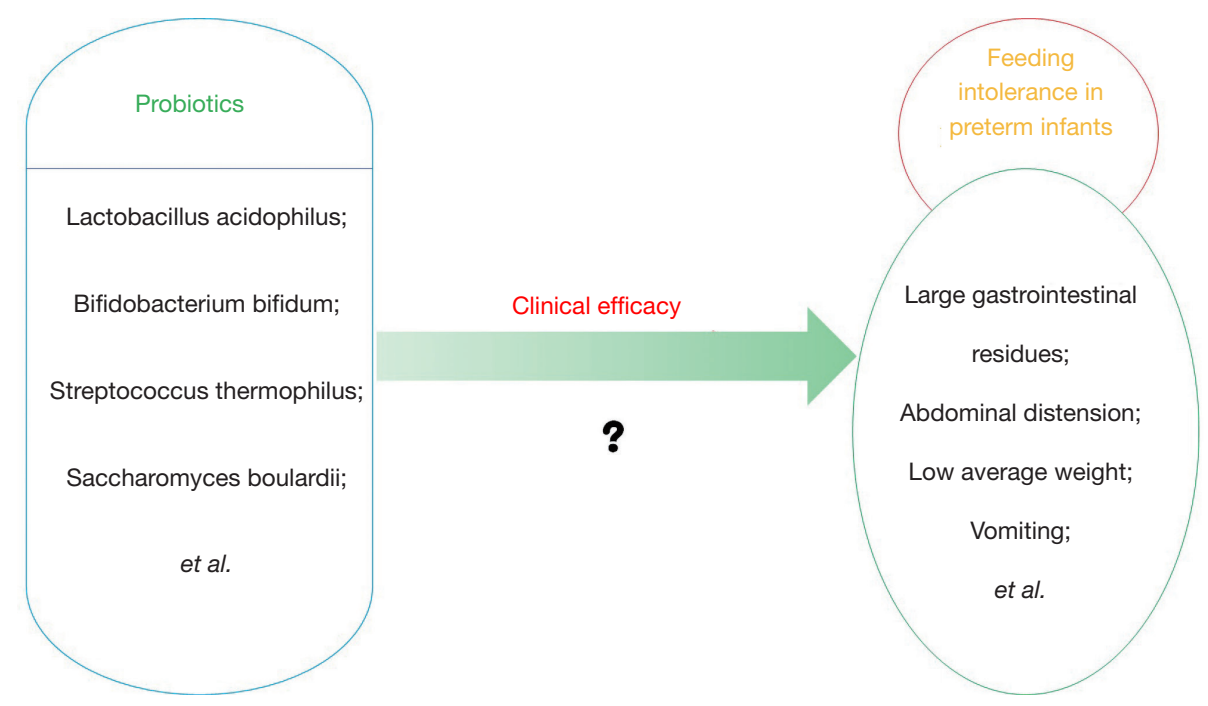

Figure 1 The possible clinical effects of probiotics on feeding intolerance in preterm infants.

and erythromycin, and nutritional interventions play a very important role and clinical research significance in promoting the growth and development of preterm infants, improving the quality of life and improving the occurrence of FI. Among these interventions, supplementing preterm infants with probiotics, such as Lactobacillus acidophilus, Enterococcus faecalis, Streptococcus thermophilus and Saccharomyces boulardii, can not only effectively improve their feeding and gastrointestinal system function but also effectively reduce and prevent the invasion and reproduction of various harmful pathogens For example, Enterococcus faecalis, as a typical representative of grampositive cocci, grows rapidly and has strong adaptability. It can inhibit the growth of Escherichia coli and it is considered to have a protective effect in FI of preterm infants (5). For another example, As a typical representative of yeast, Saccharomyces boulardii is not easy to be damaged by gastric acid and antibiotics. It will not colonize the intestine after oral administration and it can inhibit the excessive growth of pathogenic bacteria and regulate the intestinal micro ecosystem (6). In addition, this method can also build a good intestinal microbiota balance system for preterm infants, promote digestion and improve their feeding tolerance $(7,8)$ (see Figure 1). Meta-analysis was used to further explore the clinical efficacy of probiotics on FI in preterm infants.

We present the following article in accordance with the PRISMA reporting checklist (available at https:// tp.amegroups.com/article/view/10.21037/tp-21-624/rc).

\section{Methods}

\section{Data source and search strategy}

PubMed, Web of Science, EMBASE and MEDLINE literature databases were searched for relevant literature. At the same time, Website, Organisations and Citation searching were also used as other sources of literature data in this study. When conducting literature retrieval, English was limited to the language for literature retrieval, and the publication time was limited to 2002 to 2021. The literature retrieval methods were rapid retrieval of English words and combinatorial retrieval of literature keywords. The search keywords were "probiotics", "preterm infants", "feeding intolerance", "clinical efficacy", "clinical trials", and "randomized controlled trials". The free combination of these keywords was used for database full-text retrieval. At the same time, relevant citations were also tracked by manual retrieval. The retrieval time was October 20, 2021.

\section{Inclusion criteria}

(I) A randomized controlled study on the clinical effect of probiotics on FI in preterm infants; (II) the study evaluated the clinical efficacy of probiotics on FI of preterm infants, the data are complete, and the intervention group is comparable with the control group; (III) the intervention 
measure is to add probiotics, without limiting the type, dose, course of treatment of probiotics and whether to use a variety of probiotics in a combined treatment; (IV) the subjects were premature infants, but their sex, age and mode of delivery were not restricted; (V) the study reported the main outcome indicators selected in this paper.

\section{Exclusion criteria}

(I) The subjects were non-preterm infants; (II) not a randomized controlled trial; (III) the data were incomplete or cannot provide the relevant data required for analysis in this paper; (IV) duplicated data sets repeatedly published; (V) the premature infants included suffered from serious diseases, such as congenital heart disease, gastrointestinal malformation, etc.

\section{Selection of literature}

Two independent researchers screened the literature. All literature titles and abstracts were read and compared by these two researchers. Then, the irrelevant papers were excluded. The other studies were obtained and read in full text by the two researchers. After that, the two researchers performed cross-checking to exclude controversial papers. If necessary, a third person was introduced to assist in arbitration.

\section{Data extraction}

Two researchers independently extracted the relevant data and information included in our study, mainly including the first author, the time of literature publication, the number of cases of FI in preterm infants and the control group, the birth gestational age, weight, sex ratio, etc. The data were extracted and analyzed independently by two authors. In cases of divergent opinions, a comprehensive evaluation was conducted by a third party.

\section{Literature quality assessment}

In this study, the Newscast Ottawa news broadcasting scale (NOS score method) was used. Among them, 1 article scored 8 points, 1 scored 7 points, 5 articles scored 6 points and 2 articles scored 5 points, with good quality. The higher the score, the better the literature quality and the lower the risk of bias.

\section{Statistical analysis}

(I) Revman5.3 software provided by the Cochrane Collaboration Network was used for meta-analysis; (II) The combined effect size was reported using the weighted mean difference (MD), odds rate (OR) and 95\% CI, and the results were displayed using forest plots; (III) The heterogeneity among the studies was tested by the Q test. If there was no statistical heterogeneity among the results ( $\left.\mathrm{P}>0.1, \mathrm{I}^{2} \leq 50 \%\right)$, a fixed-effects model was used to analyze the data. If there was statistical heterogeneity among the research results $\left(\mathrm{P} \leq 0.1, \mathrm{I}^{2}>50 \%\right)$, we first checked whether the data reported in the studies were correct; then, we carefully read the full text of the included literature to judge whether there was obvious clinical heterogeneity or methodological heterogeneity; then, we conducted sensitivity analyses on the outcome indicators one by one, and merged the new data each time a study was removed to see whether there was any change in the size of the effect. If the result after each study's omission was about the same as the total combined result, it indicated that the results are relatively robust. If the above methods still could not explain the causes of heterogeneity, the data were combined and analyzed by a random-effects model. (IV) For all of the above effect analyses, $\mathrm{P}<0.1$ was considered to be statistically significant.

\section{Results}

\section{Literature search and screening results}

The literature searches identified a total of 552 studies. After 525 studies were filtered out, the remaining 27 studies were included in the primary screening, and 9 studies were finally included, involving a total of 1,244 patients with FI of preterm infants, as shown in Figure 2. Basic and common characteristics of the literature, as well as the excluded literature and the reasons for exclusion, are listed in Table 1.

\section{Literature quality evaluation}

Nine studies were finally included in this study. A total of 1,244 patients were included in these 9 studies. Among them, there were 626 cases in the study group and 599 cases in the control group. The average gestational age, sex ratio and weight of the preterm infants with FI between the control and case groups were not statistically significant. Among the included studies, those with an average NOS 

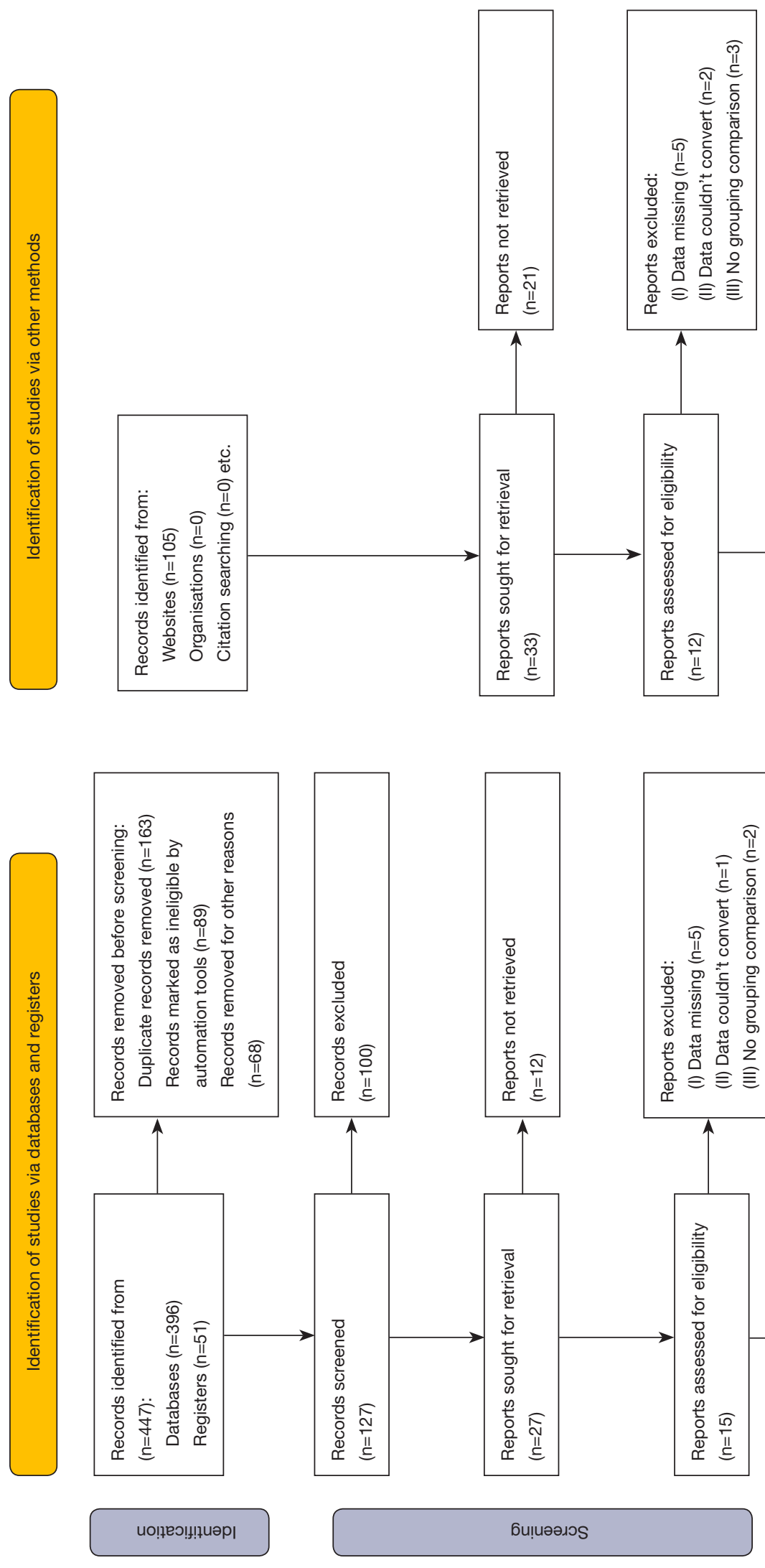

ป⿱艹 
Table 1 Excluded literature and reasons for exclusion

\begin{tabular}{lccc}
\hline Serial number & Author & Date of publication & Reason for exclusion \\
\hline 1 & Denkel LA et al. (9) & 2016 & No group comparison data \\
2 & Al-Hosni M et al. (10) & 2012 & No group comparison data \\
3 & Qiao LX et al. (11) & 2017 & Not enough data \\
4 & Spreckels JE (12) & 2021 & Data cannot be transformed \\
\hline
\end{tabular}

Table 2 Summary of basic characteristics of the included literature

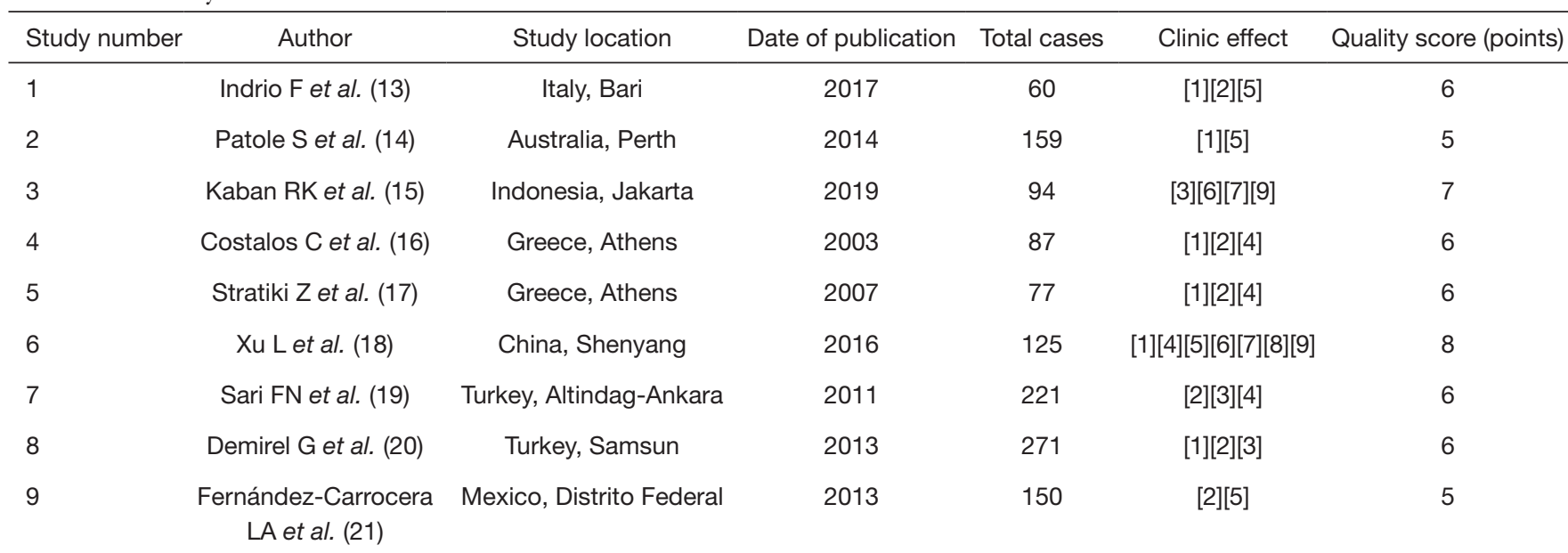

[1] Time to reach full enteral feeds; [2] weight gain; [3] incidence of feeding intolerance; [4] maximum enteral feeding; [5] time of hospital stay; [6] gastrointestinal symptoms; [7] vomiting; [8] gastric residuals; [9] abdominal distension.

$\geq 5$ stars are high-quality studies. The general information of these studies is shown in Table 2.

\section{Meta-analysis results}

\section{Time to reach full enteral feeds}

Six studies $(13,14,16-18,20)$ reported the clinical effect of probiotics on the total intestinal feeding time of preterm infants, including 394 cases in the experimental group and 366 cases in the control group. There was heterogeneity among the studies $\left(\mathrm{I}^{2}=96 \%, \mathrm{P}<0.00001\right)$. No cause of heterogeneity was found through analysis, so a randomeffects model was used for data analysis. The results showed that the clinical effect in the study group on the time to achieve total intestinal feeding was better than that of the control group, with a significant difference $(M D=-2.54$, 95\% CI: $-3.57,-1.52, \mathrm{P}<0.00001)$, as shown in Figure 3.

\section{Weight gain}

Six studies $(13,16,17,19-21)$ reported the clinical effect of probiotics on the weight gain of preterm infants, including 442 cases in the experimental group and 424 cases in the control group. There was heterogeneity among the studies $\left(\mathrm{I}^{2}=96 \%, \mathrm{P}<0.00001\right)$. No cause of heterogeneity was found through analysis, so a random-effects model was used for data analysis. The results showed that the clinical effect of probiotics on the weight gain of preterm infants in the study group was better than that in the control group, with a significant difference ( $M D=23.81,95 \%$ CI: $19.75,27.87$, $\mathrm{P}<0.00001)$, as shown in Figure 4.

\section{Maximum enteral feeding}

Three studies $(16,17,19)$ reported the clinical effect of probiotics on the maximum enteral feeding of preterm infants, including 202 cases in the experimental group and 


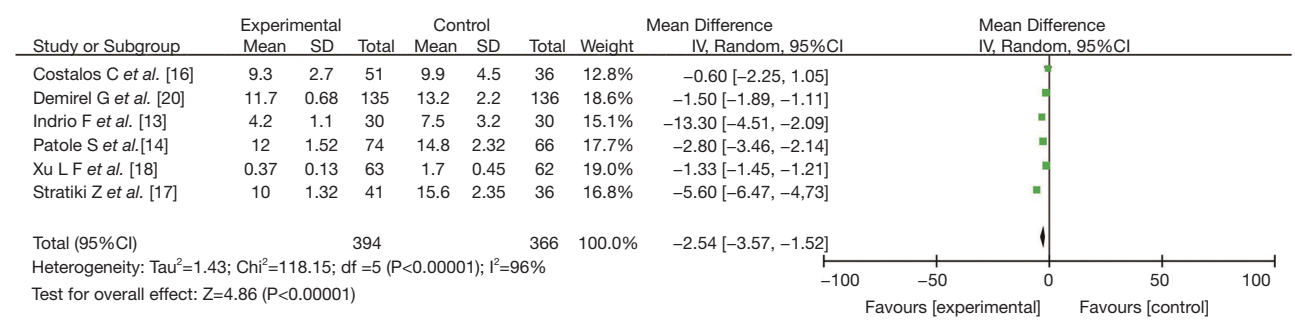

Figure 3 The effect of probiotics on the time to reach full enteral feeds in preterm infants.

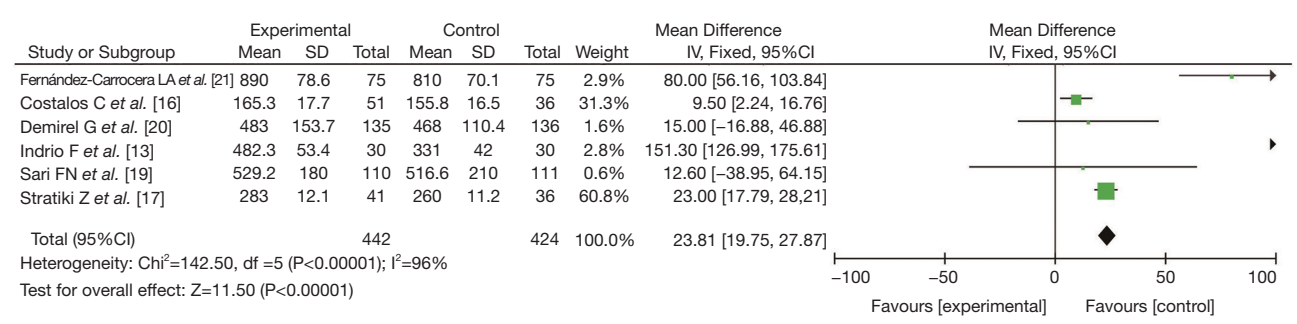

Figure 4 The effect of probiotics on weight gain in preterm infants.

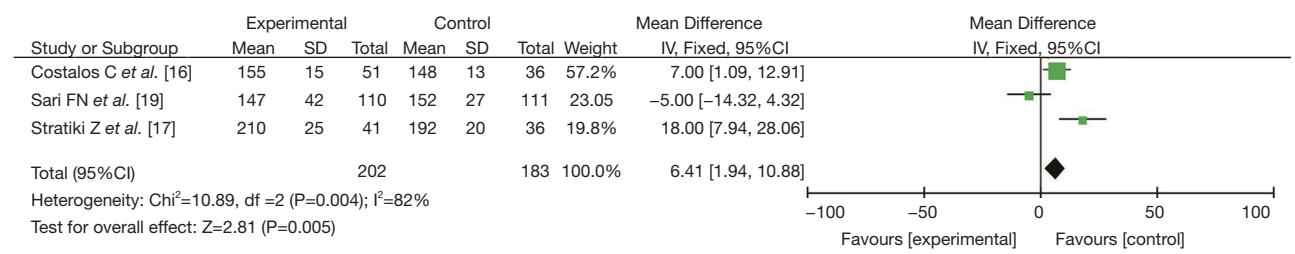

Figure 5 The effect of probiotics on maximum enteral feeding in preterm infants.

183 cases in the control group. There was heterogeneity among the studies $\left(\mathrm{I}^{2}=82 \%, \mathrm{P}=0.004\right)$. No cause of heterogeneity was found through analysis, so a randomeffects model was used for data analysis. The results showed that the clinical effect of probiotics on the maximum enteral feeding of preterm infants in the study group was better than that in the control group, with a significant difference ( $\mathrm{MD}=6.41,95 \% \mathrm{CI}: 1.94,10.88, \mathrm{P}=0.005)$, as shown in Figure 5 .

\section{Time of hospital stay}

Four studies $(13,14,18,21)$ reported the clinical effect of probiotics on the hospitalization time of preterm infants, including 242 cases in the experimental group and 233 cases in the control group. There was heterogeneity among the studies $\left(\mathrm{I}^{2}=92 \%, \mathrm{P}<0.00001\right)$. No cause of heterogeneity was found through analysis, so a random-effects model was used for data analysis. The results showed that the clinical effect of probiotics on the hospitalization time of preterm infants in the study group was better than that in the control group, with a significant difference (MD $=-5.18,95 \% \mathrm{CI}:-5.63$, -4.74, $\mathrm{P}<0.00001)$, as shown in Figure 6.

\section{Incidence of FI}

Three studies $(15,19,20)$ reported the clinical effect of probiotics on the incidence of FI in preterm infants, including 292 cases in the experimental group and 294 cases in the control group. There was no heterogeneity among the studies $\left(\mathrm{I}^{2}=0 \%, \mathrm{P}=0.59\right)$. The fixed-effects model was used for data analysis. The results showed that the incidence of FI after giving probiotics to preterm infants was significantly lower than that of the control group, and the difference was statistically significant (OR $=0.38,95 \%$ CI: $0.27,0.55, \mathrm{P}<0.00001$ ), as shown in Figure 7.

\section{Gastrointestinal symptoms}

Two studies $(15,18)$ reported the clinical effect of probiotics on the improvement of the gastrointestinal tract of preterm 


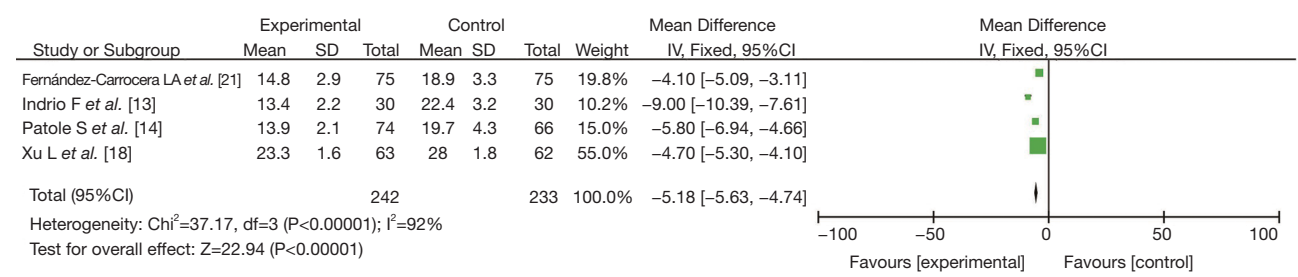

Figure 6 The effect of probiotics on the time to reach full enteral feeds in preterm infants.

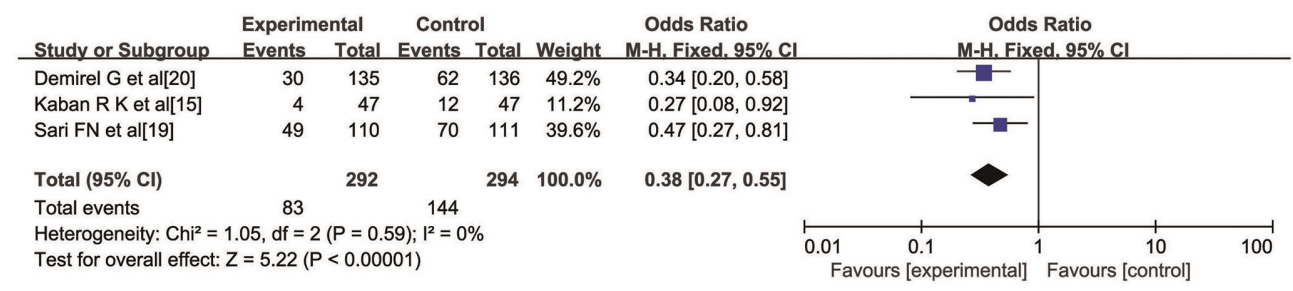

Figure 7 The effect of probiotics on the incidence of feeding intolerance in preterm infants.

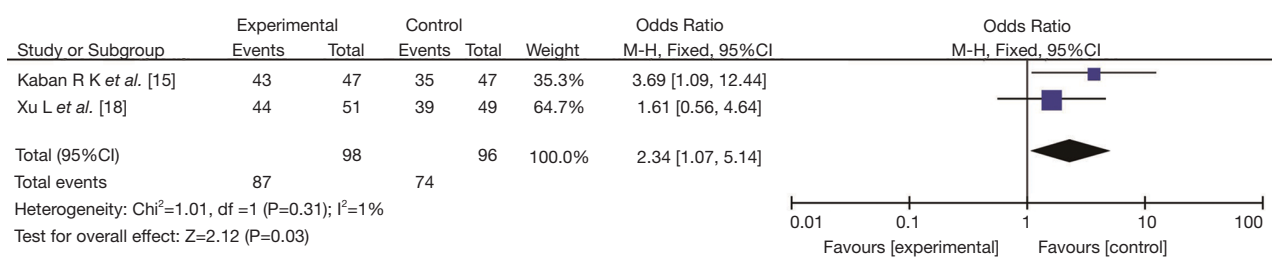

Figure 8 The effect of probiotics on gastrointestinal symptoms in preterm infants.

infants, including 98 cases in the experimental group and 96 cases in the control group. There was no heterogeneity among the studies $\left(\mathrm{I}^{2}=1 \%, \mathrm{P}<0.31\right)$. The fixed-effects model was used for data analysis. The results showed that the clinical effect of the study group after using probiotics was better than that of the control group, with a significant difference $(\mathrm{OR}=2.34,95 \% \mathrm{CI}: 1.07,5.14, \mathrm{P}=0.03)$, as shown in Figure 8.

\section{Analysis of publication bias}

Publication bias analysis was not performed because fewer than 10 articles were included in this review.

\section{Discussion}

Due to the immature development of various physiological organs of preterm infants, the volume of the gastrointestinal tract is small, the number and types of bacterial colonization are small, and the barrier function of the gastrointestinal tract is relatively weak. These factors not only cause nutritional imbalance and dysplasia but also easily lead to
FI. For example, vomiting, gastrointestinal dysfunction, diarrhea, gastric retention and poor bowel movements are the most typical clinical manifestations of preterm infants. Therefore, effective interventions by supplying nutrients $(22)$, drugs $(23,24)$ or probiotics $(25,26)$ has very important clinical value and research significance for improving the physiological status and quality of life of preterm infants.

As an active microorganism that can produce beneficial effects on host health, probiotics include not only various beneficial bacteria but also some beneficial fungi, such as Bifidobacterium, Lactobacillus, yeast, Clostridium butyricum, Bacillus, and Enterococcus $(27,28)$. These probiotics of beneficial bacteria or fungi play an important role in improving the digestive function of the human gastrointestinal tract. Especially for premature infants, supplementation with probiotics can not only establish a normal balance of the gastrointestinal flora microecosystem but also effectively absorb all kinds of nutrients to achieve improved early growth and development (29). At the same time, probiotics can also improve the immune function 
of preterm infants in varying degrees (30). For example, Bifidobacterium longum can accelerate the maturation of immune response, balance the immune system to inhibit inflammation and improve intestinal barrier function, which is beneficial to the host (31). At present, the clinical treatment of probiotics combined with other drugs or methods in the treatment of FI in preterm infants has been reported, such as probiotics combined with Mosapride, erythromycin and other drugs (32). Although this combination regimen has achieved clinical results, more clinical sample data and data are needed to further verify because there are many related factors involved in the combination therapy and it is more prone to adverse drug reactions.

Supplementing probiotics can promote the colonization and dominance of normal intestinal flora in preterm newborns, play a beneficial role in preterm newborns, and have great clinical value. However, the clinical research of probiotics in preterm infants is still in its infancy, there are still few data on the safety and effectiveness of probiotics, and there are still disputes on the long-term consequences of iatrogenic colonization after the application of probiotics. Therefore, it is necessary to carry out larger-scale research and verification on its safety and effectiveness, so as to better evaluate the benefits and risks of probiotics in preterm infants (33).

The meta-analysis results of this study showed that after probiotic supplementation, the probiotic group achieved a total intestinal feeding time $(\mathrm{MD}=-2.54,95 \% \mathrm{CI}:-3.57$, $-1.52, \mathrm{P}<0.00001)$, weight gain ( $\mathrm{MD}=23.81,95 \% \mathrm{CI}: 19.75$, $27.81, \mathrm{P}<0.00001)$, maximum enteral feeding $(\mathrm{MD}=6.41$, 95\% CI: $1.94,10.88, \mathrm{P}=0.005)$ and reduced hospital stay $(\mathrm{MD}=-5.18,95 \% \mathrm{CI}:-5.63,-4.74, \mathrm{P}<0.00001)$, a reduced incidence of FI (OR $=0.38,95 \% \mathrm{CI}: 0.27,0.55, \mathrm{P}<0.00001)$ and an improvement of the gastrointestinal tract $(\mathrm{OR}=2.34$, 95\% CI: $1.07,5.14, \mathrm{P}=0.03)$ that were all significantly better than the control group $(\mathrm{P}<0.1)$. Therefore, these data show that probiotics have a good clinical effect on the FI of infants.

\section{Conclusions}

In this meta-analysis of the clinical effect of probiotics on FI in preterm infants, a total of 9 studies were included. The results showed that probiotics had a good clinical effect on preterm infants with FI in terms of total intestinal feeding time, weight gain, maximum enteral feeding amount, length of hospital stay, incidence of FI and improvement of the gastrointestinal tract.

\section{Acknowledgments}

Funding: This project was supported by Hainan Province Clinical Medical Center.

\section{Footnote}

Reporting Checklist: The authors have completed the PRISMA reporting checklist. Available at https:// tp.amegroups.com/article/view/10.21037/tp-21-624/rc

Conflicts of Interest: All authors have completed the ICMJE uniform disclosure form (available at https://tp.amegroups. com/article/view/10.21037/tp-21-624/coif). The authors have no conflicts of interest to declare.

Ethical Statement: The authors are accountable for all aspects of the work in ensuring that questions related to the accuracy or integrity of any part of the work are appropriately investigated and resolved.

Open Access Statement: This is an Open Access article distributed in accordance with the Creative Commons Attribution-NonCommercial-NoDerivs 4.0 International License (CC BY-NC-ND 4.0), which permits the noncommercial replication and distribution of the article with the strict proviso that no changes or edits are made and the original work is properly cited (including links to both the formal publication through the relevant DOI and the license). See: https://creativecommons.org/licenses/by-nc-nd/4.0/.

\section{References}

1. Fanaro S. Feeding intolerance in the preterm infant. Early Hum Dev 2013;89 Suppl 2:S13-20.

2. Lucchini R, Bizzarri B, Giampietro S, et al. Feeding intolerance in preterm infants. How to understand the warning signs. J Matern Fetal Neonatal Med 2011;24 Suppl 1:72-4.

3. Moore TA, Pickler RH. Feeding intolerance, inflammation, and neurobehaviors in preterm infants. J Neonatal Nurs 2017;23:134-41.

4. Omar OM, Massoud MN, Ghazal H, et al. Effect of enteral erythropoietin on feeding-related complications in preterm newborns: A pilot randomized controlled study. Arab J Gastroenterol 2020;21:37-42. 
5. Deshpande G, Jape G, Rao S, et al. Benefits of probiotics in preterm neonates in low-income and medium-income countries: a systematic review of randomised controlled trials. BMJ Open 2017;7:e017638.

6. Bommer C, Horn S, Vollmer S. The effect of routine probiotics supplementation on preterm newborn health: a regression discontinuity analysis. Am J Clin Nutr 2020;112:1219-27.

7. Wieërs G, Belkhir L, Enaud R, et al. How Probiotics Affect the Microbiota. Front Cell Infect Microbiol 2020;9:454.

8. Kim SK, Guevarra RB, Kim YT, et al. Role of Probiotics in Human Gut Microbiome-Associated Diseases. J Microbiol Biotechnol 2019;29:1335-40.

9. Denkel LA, Schwab F, Garten L, et al. Protective Effect of Dual-Strain Probiotics in Preterm Infants: A Multi-Center Time Series Analysis. PLoS One 2016;11:e0158136.

10. Al-Hosni M, Duenas M, Hawk M, et al. Probioticssupplemented feeding in extremely low-birth-weight infants. J Perinatol 2012;32:253-9.

11. Qiao LX, Zhu WY, Zhang HY, Wang H. Effect of early administration of probiotics on gut microflora and feeding in pre-term infants: a randomized controlled trial. J Matern Fetal Neonatal Med 2017;30:13-6.

12. Spreckels JE, Wejryd E, Marchini G, et al. Lactobacillus reuteri Colonisation of Extremely Preterm Infants in a Randomised Placebo-Controlled Trial. Microorganisms 2021;9:915.

13. Indrio F, Riezzo G, Tafuri S, et al. Probiotic Supplementation in Preterm: Feeding Intolerance and Hospital Cost. Nutrients 2017;9:965.

14. Patole S, Keil AD, Chang A, Nathan E, Doherty D, Simmer K, Esvaran M, Conway P. Effect of Bifidobacterium breve M-16V supplementation on fecal bifidobacteria in preterm neonates--a randomised double blind placebo controlled trial. PLoS One 2014;9:e89511.

15. Kaban RK, Wardhana, Hegar B, et al. Lactobacillus reuteri DSM 17938 Improves Feeding Intolerance in Preterm Infants. Pediatr Gastroenterol Hepatol Nutr 2019;22:545-53.

16. Costalos C, Skouteri V, Gounaris A, et al. Enteral feeding of premature infants with Saccharomyces boulardii. Early Hum Dev 2003;74:89-96.

17. Stratiki Z, Costalos C, Sevastiadou S, et al. The effect of a bifidobacter supplemented bovine milk on intestinal permeability of preterm infants. Early Hum Dev 2007;83:575-9.

18. Xu L, Wang Y, Wang Y, Fu J, Sun M, Mao Z, Vandenplas
Y. A double-blinded randomized trial on growth and feeding tolerance with Saccharomyces boulardii CNCM I-745 in formula-fed preterm infants. J Pediatr (Rio J) 2016;92:296-301.

19. Sari FN, Dizdar EA, Oguz S, et al. Oral probiotics: Lactobacillus sporogenes for prevention of necrotizing enterocolitis in very low-birth weight infants: a randomized, controlled trial. Eur J Clin Nutr 2011;65:434-9.

20. Demirel G, Erdeve O, Celik IH, et al. Saccharomyces boulardii for prevention of necrotizing enterocolitis in preterm infants: a randomized, controlled study. Acta Paediatr 2013;102:e560-5.

21. Fernández-Carrocera LA, Solis-Herrera A, CabanillasAyón M, et al. Double-blind, randomised clinical assay to evaluate the efficacy of probiotics in preterm newborns weighing less than $1500 \mathrm{~g}$ in the prevention of necrotising enterocolitis. Arch Dis Child Fetal Neonatal Ed 2013;98:F5-9.

22. Griffin MP, Hansen JW. Can the elimination of lactose from formula improve feeding tolerance in premature infants? J Pediatr 1999;135:587-92.

23. Oei J, Lui K. A placebo-controlled trial of low-dose erythromycin to promote feed tolerance in preterm infants. Acta Paediatr 2001;90:904-8.

24. Gounaris A, Costalos C, Varchalama E, et al. Gastric emptying of preterm neonates receiving domperidone. Neonatology 2010;97:56-60.

25. Sari FN, Eras Z, Dizdar EA, et al. Do oral probiotics affect growth and neurodevelopmental outcomes in very low-birth-weight preterm infants? Am J Perinatol 2012;29:579-86.

26. Athalye-Jape G, Deshpande G, Rao S, et al. Benefits of probiotics on enteral nutrition in preterm neonates: a systematic review. Am J Clin Nutr 2014;100:1508-19.

27. Williams NT. Probiotics. Am J Health Syst Pharm 2010;67:449-58.

28. Sanders ME. Probiotics in 2015: Their Scope and Use. J Clin Gastroenterol 2015;49 Suppl 1:S2-6.

29. Piqué N, Berlanga M, Miñana-Galbis D. Health Benefits of Heat-Killed (Tyndallized) Probiotics: An Overview. Int J Mol Sci 2019;20:2534.

30. Bell SG. Immunomodulation, Part V: probiotics. Neonatal Netw 2007;26:57-60.

31. Chichlowski M, Shah N, Wampler JL, Wu SS, Vanderhoof JA. Bifidobacterium longum Subspecies infantis (B. infantis) in Pediatric Nutrition: Current State of Knowledge. Nutrients 2020;12:1581. 
32. Zhang AM, Sun ZQ, Zhang LM. Mosapride combined with probiotics on gastrointestinal function and growth in premature infants. Exp Ther Med 2017;13:2675-80.

Cite this article as: Zhang W, Wang S, Xing Y, Wang H, Fu B, Long M, Cao J. Clinical efficacy of probiotics on feeding intolerance in preterm infants: a systematic review and metaanalysis. Transl Pediatr 2022;11(2):229-238. doi: 10.21037/tp21-624
33. Miller M, Burjonrappa S. A review of enteral strategies in infant short bowel syndrome: evidence-based or NICU culture? J Pediatr Surg 2013;48:1099-112. 